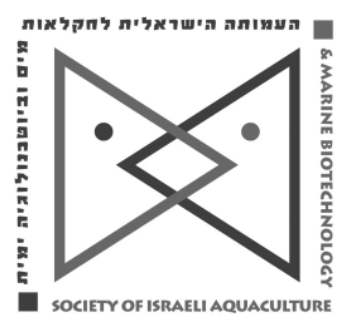

The IJA appears exclusively as a peer-reviewed on-line open-access journal at http://www.siamb.org.il. To read papers free of charge, please register online at registration form.

Sale of $I J A$ papers is strictly forbidden.

\title{
Effects of Biofloc on Plankton Abundance in the Water
}

\author{
Wei Nie ${ }^{1}$,Wen Liu ${ }^{1}$,Li-He Liu ${ }^{1}{ }^{*}$, Deng-Hang $\mathrm{Yu}^{1}{ }^{1}$, Jun Liu ${ }^{1}, \mathrm{Zhe} \mathrm{Zhou}^{2}$ \\ ${ }^{1}$ College of Animal Science and Nutritional Engineering, Wuhan Polytechnic \\ University, Wuhan, 430023
}

${ }^{2}$ BIOMAX Ecological Engineering Limited by Share Ltd, Nanjing, 210019

Keywords: biofloc; glucose; Bacillus subtilis; water quality indicators; plankton

\begin{abstract}
This study was conducted to evaluate the effects of biofloc on the species and quantity of plankton in pond water. There were four treatments in the experiment: the control, no supplementation; treatment I, pond water supplemented with glucose; treatment II, pond water supplemented with both glucose and Bacillus subtilis; and treatment III, pond water supplemented with Bacillus subtilis only. Water quality, plankton, and biofloc formation were monitored every five days. Results showed that biofloc formation was enhanced by adding glucose to the pond water. The addition of glucose together with Bacillus subtilis shortened the formation time of mature bioflocs by about five days than the supplementation with glucose only. In ponds supplemented with glucose and those supplemented with glucose + bacillus, the ammonia nitrogen, and nitrite nitrogen content in the water column decreased, and the number of cyanobacteria and green algae were significantly inhibited, while the number of zooplankton such as Rotatoria increased during the experimental period.
\end{abstract}

The first two authors contributed equally to this work.

*Corresponding author: Tel: +862783956175; Fax: +862783956175;

Email:763826895@qq.com 


\section{Introduction}

Aquaculture is an important food industry that needs to be developed in environmentally sustainable systems. Aquaculture production provides a reliable food source but its rapid expansion sometimes has a negative impact on natural environments. Previous studies have focused mainly on treatments of dissolved waste such as ammonium and nitrite (Neori et al., 2004). In recent years a new type of environmentally friendly Biofloc technology (BFT) has emerged, and is being currently used in aquaculture.

The BFT system is based on minimal effluent discharges thereby protecting surrounding water resources and improving farm biosecurity (Burford et al. 2003; Avnimelech, 2007). This system not only effectively controls water quality but also provides a sustainable, intensive and healthy environment for aquatic animals in culture. (Stokstad, 2010). The system is based on the principle of assimilation of excreted dissolved nitrogen by heterotrophic bacteria, and management of the $\mathrm{C} / \mathrm{N}$ ratio in the water (Avnimelech, 1999). Previous studies on BFT in aquaculture have concentrated on shrimp and tilapia farming (Ray et al., 2017).

In this study, glucose and Bacillus subtilis were added, individually and in combination, to the culture water to enhance the process of biological flocculation, plankton species, and the dynamics of biofloc formation. Our work provides a theoretical basis for further studies on biological flocculation.

\section{Materials and methods}

Experimental design. The 40 day experiment was conducted in 12 indoor fiberglass aquaria $(80 \mathrm{~cm} \times 60 \mathrm{~cm} \times 50 \mathrm{~cm})$ with a water volume of $200 \mathrm{~L}$ each. Four treatments were compared (Table 1): Treatment I (T1) water supplemented with glucose only; treatment II (T2) water supplemented with glucose and Bacillus subtilis; treatment III (T3) water supplemented with Bacillus subtilis, and the control (C) which had no added supplements. All aquaria were the same size, and each treatment was replicated three times. The amount of glucose and Bacillus subtilis added were the same in both treatments. The amount of glucose added was calculated based on Avnimelech (1999) and the carbon and nitrogen ratio was 20:1. The number of Bacillus subtilis added was $10^{9} \mathrm{CFU} / \mathrm{L}$. During the entire experimental period, water was maintained at $25 \pm 0.5^{\circ} \mathrm{C}$, and was continuously aerated; photoperiod was $12 \mathrm{~h}$ light/12 h dark. All aquaria received adequate fresh water to compensate for water loss.

Table 1. The changes of the water quality index in all aquaria during the experimental period. Values are means ( \pm S.D.) of three replicate aquariums per sampling time in each treatment.

\begin{tabular}{|c|c|c|c|c|c|c|c|c|c|c|}
\hline & \multicolumn{9}{|c|}{ Sampling time (day) } \\
\hline & & 1 & 5 & 10 & 15 & 20 & 25 & 30 & 35 & 40 \\
\hline \multirow{4}{*}{ DO } & I & $8.58 \pm 0.11$ & $7.82 \pm 0.10$ & $7.05 \pm 0.08$ & $6.43 \pm 0.10$ & $5.61 \pm 0.07$ & $5.77 \pm 0.08$ & $5.93 \pm 0.09$ & $5.84 \pm 0.08$ & $6.06 \pm 0.07$ \\
\hline & II & $8.61 \pm 0.09$ & $7.33 \pm 0.05$ & $6.12 \pm 0.06$ & $5.23 \pm 0.13^{*}$ & $5.57 \pm 0.08$ & $5.64 \pm 0.07$ & $5.83 \pm 0.11$ & $5.95 \pm 0.07$ & $5.82 \pm 0.10$ \\
\hline & III & $8.62 \pm 0.12$ & $8.15 \pm 0.07$ & $8.09 \pm 0.08$ & $8.18 \pm 0.07$ & $8.24 \pm 0.10$ & $8.31 \pm 0.11$ & $8.38 \pm 0.08$ & $8.49 \pm 0.05$ & $8.48 \pm 0.12$ \\
\hline & control & $8.57 \pm 0.11$ & $8.45 \pm 0.04$ & $8.33 \pm 0.05$ & $8.46 \pm 0.09$ & $8.42 \pm 0.08$ & $8.43 \pm 0.06$ & $8.51 \pm 0.12$ & $8.50 \pm 0.11$ & $8.49 \pm 0.09$ \\
\hline \multirow{4}{*}{ pH } & I & $7.38 \pm 0.02$ & $7.16 \pm 0.06$ & $7.05 \pm 0.04$ & $6.82 \pm 0.01$ & $6.77 \pm 0.03$ & $6.85 \pm 0.05$ & $6.89 \pm 0.04$ & $6.80 \pm 0.02$ & $6.85 \pm 0.01$ \\
\hline & II & $7.36 \pm 0.01$ & $7.03 \pm 0.03$ & $6.74 \pm 0.05$ & $6.61 \pm 0.05$ & $6.77 \pm 0.04$ & $6.93 \pm 0.03$ & $6.95 \pm 0.03$ & $6.91 \pm 0.02$ & $7.03 \pm 0.06$ \\
\hline & III & $7.38 \pm 0.01$ & $7.21 \pm 0.02$ & $7.14 \pm 0.03$ & $7.15 \pm 0.01$ & $7.24 \pm 0.02$ & $7.26 \pm 0.02$ & $7.19 \pm 0.03$ & $7.18 \pm 0.05$ & $7.23 \pm 0.04$ \\
\hline & control & $7.37 \pm 0.02$ & $7.35 \pm 0.03$ & $7.23 \pm 0.03$ & $7.28 \pm 0.02$ & $7.25 \pm 0.04$ & $7.27 \pm 0.03$ & $7.21 \pm 0.02$ & $7.18 \pm 0.03$ & $7.18 \pm 0.03$ \\
\hline \multirow{4}{*}{$\mathrm{NO}_{2}-\mathrm{N}$} & I & $0.22 \pm 0.01$ & $0.24 \pm 0.01$ & $0.27 \pm 0.01$ & $0.19 \pm 0.01$ & $0.08 \pm 0.01 *$ & $0.07 \pm 0.01 *$ & $0.06 \pm 0.01 *$ & $0.04 \pm 0.01 *$ & $0.06 \pm 0.01 *$ \\
\hline & II & $0.22 \pm 0.01$ & $0.26 \pm 0.01$ & $0.19 \pm 0.01$ & $0.06 \pm 0.01 *$ & $0.06 \pm 0.01 *$ & $0.06 \pm 0.01 *$ & $0.04 \pm 0.01 *$ & $0.05 \pm 0.01 *$ & $0.05 \pm 0.01 *$ \\
\hline & III & $0.21 \pm 0.01$ & $0.20 \pm 0.01$ & $0.18 \pm 0.01$ & $0.19 \pm 0.01$ & $0.16 \pm 0.01$ & $0.16 \pm 0.01$ & $0.14 \pm 0.01$ & $0.13 \pm 0.01$ & $0.13 \pm 0.01$ \\
\hline & control & $0.22 \pm 0.01$ & $0.22 \pm 0.01$ & $0.23 \pm 0.01$ & $0.21 \pm 0.01$ & $0.180 \pm 0.01$ & $0.17 \pm 0.01$ & $0.16 \pm 0.01$ & $0.14 \pm 0.01$ & $0.16 \pm 0.01$ \\
\hline \multirow{4}{*}{$\mathrm{NO}_{3}--\mathrm{N}$} & I & $1.26 \pm 0.13$ & $1.49 \pm 0.12$ & $1.72 \pm 0.10$ & $2.89 \pm 0.09 *$ & $2.51 \pm 0.11^{*}$ & $2.75 \pm 0.08^{*}$ & $2.39 \pm 0.11^{*}$ & $2.16 \pm 0.09 *$ & $2.21 \pm 0.07 *$ \\
\hline & II & $1.25 \pm 0.10$ & $1.57 \pm 0.11$ & $1.85 \pm 0.13$ & $2.32 \pm 0.10 *$ & $2.14 \pm 0.09 *$ & $1.91 \pm$ & $2.01 \pm 0$ & 1 . & 1.2 \\
\hline & & & & & $1.07 \pm 0.08$ & & & & & \\
\hline & control & $1.25 \pm 0.12$ & $1.23 \pm 0.13$ & $1.33 \pm 0.09$ & $1.23 \pm 0.11$ & $1.36 \pm 0.10$ & $1.38 \pm 0.08$ & $1.31 \pm 0.09$ & $1.24 \pm 0.10$ & $1.19 \pm 0.11$ \\
\hline \multirow{4}{*}{$\mathrm{NH}_{4}--\mathrm{N}$} & I & $0.64 \pm 0.03$ & $0.67 \pm 0.02$ & $0.52 \pm 0.02$ & $0.45 \pm 0.03$ & $0.23 \pm 0.02 *$ & $0.18 \pm 0.03 *$ & $0.21 \pm 0.01 *$ & $0.13 \pm 0.02 *$ & $0.14 \pm 0.02 *$ \\
\hline & II & $0.64 \pm 0.01$ & $0.58 \pm 0.01$ & $0.41 \pm 0.02$ & $0.32 \pm 0.01$ & $0.20 \pm 0.03 *$ & $0.11 \pm 0.02 *$ & $0.14 \pm 0.03 *$ & $0.11 \pm 0.01 *$ & $0.13 \pm 0.02 *$ \\
\hline & III & $0.62 \pm 0.03$ & $0.59 \pm 0.02$ & $0.53 \pm 0.03$ & $0.47 \pm 0.02$ & $0.41 \pm 0.01$ & $0.45 \pm 0.02$ & $0.42 \pm 0.01$ & $0.44 \pm 0.02$ & $0.41 \pm 0.03$ \\
\hline & control & $0.65 \pm 0.02$ & $0.64 \pm 0.03$ & $0.59 \pm 0.01$ & $0.54 \pm 0.02$ & $0.53 \pm 0.02$ & $0.48 \pm 0.01$ & $0.55 \pm 0.02$ & $0.51 \pm 0.03$ & $0.50 \pm 0.01$ \\
\hline
\end{tabular}

Treatment I (T1) : Glucose addition; Treatment II (T2) : Glucose+Bacillus addition ; Treatment III (T3) : Bacillus addition. Different superscript symbols $(*)$ denote significant differences $(p<0.05)$ within T1, T2, T3 and the control. 
Assessments of water quality. Throughout the 40-day experimental period, water temperature and $\mathrm{pH}$ were measured daily at 08:30-09:30 AM with a thermometer and $\mathrm{pH}$ meter respectively. Water samples were collected from each aquarium every 5 days,

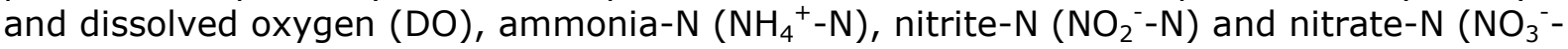
$\mathrm{N})$ were analyzed spectrophotometrically immediately after each sample collection, as described in APHA (1998).

Assessment of microorganisms: Bacterial load in the aquaria water was analyzed every five days between 08:30 and 09:30 AM. All samples were collected from 5 different locations, mixed thoroughly, transferred to sterile glass bottles and preserved with borate-buffered formalin (4\% v/v) (Thompson, Abreu \& Wasielesky 2002). One milliliter water sample was transferred with a sterile pipette to a test tube containing $9.0 \mathrm{~mL}$ of phosphate buffered saline (PBS). The tubes were then shaken thoroughly and $5.0 \mathrm{~g}$ sediment, or periphyton samples were weighed and transferred to sterile conical flasks, made up to $50 \mathrm{~mL}$ with PBS, and the contents mixed thoroughly to prepare a stock solution. Serial dilution of up to $10^{6}$ for water and $10^{9}$ for sediment and periphyton respectively were prepared with PBS. $0.1 \mathrm{ml}$ of each dilution was spread over the surface of duplicate plates of tryptone soya agar and incubated at $30^{\circ} \mathrm{C}$ for $24-48 \mathrm{~h}$. Plates with 30-300 colony forming units (CFU) were counted with a Xun Shu Colony Counter and expressed as CFU. Counts were made from 30 fields chosen at random. Free-living bacteria in the water column and attached bacteria on the various substrates in the aquaria (i.e. organic and inorganic particles, etc.) were quantified. Fifteen random floc size measures were made once every 5 days.

Assessment of the amount of biofloc formation. Water samples were collected from each aquarium every 5 days to quantify the biofloc volume (BFV). Sampling $1000 \mathrm{~mL}$ water determined total suspended solids (TSS) and biofloc volume (BFV) into a series of Imhoff cones. The volume of the biofloc plug accumulated on the bottom of the cone was also determined (Avnimelech and Kochba, 2009; Xu and Pan, 2012). Suspended biofloc in biofloc-based aquaria were collected using sterile pipets, and a Nikon inverted microscope revealed the morphological structure of the biofloc. On the last day of the experiment, the biofloc produced in the aquaria was collected.

Assessment of the plankton: Plankton samples were collected every 5 days by pooling $1000 \mathrm{~mL}$ of water from five different locations in each aquarium and passing them through a $45 \mu \mathrm{m}$ mesh plankton net. The concentrated samples were preserved in small plastic bottles with $5 \%$ buffered formalin. Qualitative and quantitative estimations of plankton were made using a Sedgewick-Rafter (S-R) cell containing 1000 fields of 1 $\mathrm{mm}^{3}$. A $1 \mathrm{ml}$ sample was put in the S-R cell and left undisturbed for $15 \mathrm{~min}$ to allow plankton to settle. The plankton in 10 randomly selected cells were identified to genus level and counted under a binocular microscope (Swift, M-4000). Planktons were identified using keys by Ward and Whipple (1959), Prescott (1962), Belcher and Swale (1976), and Bellinger (1992). Current taxonomic names [http://www.algaebase.org/ (accessed March, 2011)] of phytoplankton were used. Phytoplankton abundance was reported as natural units per liter. Plankton abundance was calculated using the following formula:

$N=(P \times C \times 100) / L$

Where $\mathrm{N}=$ the number of plankton cells or units per liter of original water;

$\mathrm{P}=$ the average number of plankton counted in 10 fields; the

$\mathrm{C}=$ the volume of concentrates $(\mathrm{mL})$;

$\mathrm{L}=$ the volume $(\mathrm{L})$ of the pond water sample.

Statistical analysis. All statistical analyses were performed with SPSS17.0 software. The differences in water quality and the abundance of plankton were considered significant when $P<0.05$. One way ANOVA was used to determine the significance of each parameter among different treatments.

\section{Results}

Physicochemical variables and assessment of microorganisms. During the experimental period, water temperature in all aquaria was maintained at $25 \pm 0.5^{\circ} \mathrm{C}$; the changes of $\mathrm{DO}$ and $\mathrm{pH}$ appear in Table 1 . The contents of DO in the T1 and the T2 increased slowly 
after a rapid decline, but there were no obvious differences between T3 and the control. DO in the T2 reached a minimum $(5.23 \pm 0.17 \mathrm{mg} / \mathrm{L})$ on day 15 . The decrease rate was significantly higher than in $\mathrm{T} 2(\mathrm{P}<0.05)$ and $\mathrm{T} 1$. Variation in trends of $\mathrm{pH}$ were similar to those of DO in all aquaria. The $\mathrm{pH}$ which ranged between 6.5-7.5 was not different than in T3 and the control ( $P>0.05)$.

Nitrite $\mathrm{NO}_{2}^{-}-\mathrm{N}$ in $\mathrm{T} 1$ and $\mathrm{T} 2$ showed similar trends; it first increased and then decreased. In $\mathrm{T} 2$ it increased rapidly and after day 15 it decreased. $\mathrm{NO}^{-}-\mathrm{N}$ concentration in $\mathrm{T} 1$ reached a peak $(0.53 \pm 0.05 \mathrm{mg} / \mathrm{L})$ on day 10 and decreased from day 10 to day 20, after which it began to decrease slowly and reached $0.11 \pm 0.01 \mathrm{mg} / \mathrm{L}$ on day 40 . $\mathrm{NO}^{-}-\mathrm{N}$ concentrations in $\mathrm{T} 3$ and control group decreased slowly during the experiment and were significantly higher $(P<0.05)$ than those in the $T 1$ and $T 2$ after day 20 . At the end of the experiment, $\mathrm{NO}^{-} \mathrm{-N}$ levels in $\mathrm{T} 1, \mathrm{~T} 2, \mathrm{~T} 3$ and control decreased by $79.07 \%$, $74.42 \%, 38.10 \%$, and $29.55 \%$, respectively. Removal rates of $\mathrm{NO}^{-}-\mathrm{N}$ in $\mathrm{T} 1$ and $\mathrm{T} 2$ were significantly higher $(\mathrm{P}<0.05)$ than those in T3 and control group.

Levels of nitrate nitrogen in T1 and T2 first increased and then decreased, while those of $\mathrm{NH}_{4}{ }^{+}-\mathrm{N}$ in $\mathrm{T} 3$ and control group fluctuated within a small range (Tab.1). In T1 and $\mathrm{T} 2$ they reached a peak of $2.89 \pm 0.11 \mathrm{mg} / \mathrm{L}, 2.32 \pm 0.08 \mathrm{mg} / \mathrm{L}$, respectively. At the end of the experiment, the level of $\mathrm{NO}_{3}^{-}-\mathrm{N}$ in $\mathrm{T} 2$ was significantly higher $(\mathrm{P}<0.05)$ than in the T1, T3 and the control group, but not significantly different than $T 1, T 3$, and the control group. The trend of $\mathrm{NH}_{4}{ }^{+}-\mathrm{N}$ in each treatment (except for $\mathrm{T} 1$ ) was similar and decreased slowly. $\mathrm{NH}_{4}{ }^{+}-\mathrm{N}$ level in $\mathrm{T} 1$ first reached a peak $(0.67 \pm 0.06 \mathrm{mg} / \mathrm{L})$ that appeared on day 5 but in T1, T2, T3 and in the control group it decreased by $78.12 \%$, $79.69 \%, 33.87 \%$ and $23.08 \%$, respectively. The contents of $\mathrm{NH}_{4}{ }^{+}-\mathrm{N}$ in T1 and $\mathrm{T} 2$ were significantly different $(\mathrm{P}<0.05)$ from those of $\mathrm{T} 3$ and the control group.

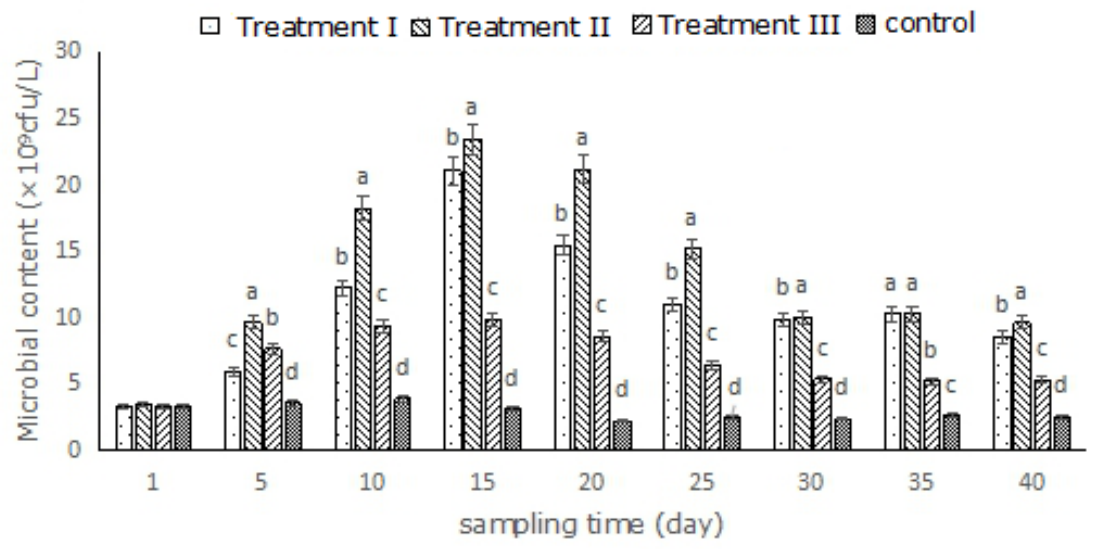

Fig1. The number of total cultivable microbes in all aquaria during the experimental period. Values are means ( \pm S.D.) of three replicate aquariums per sampling time in each treatment.

The changes of total cultivable microbes are shown in fig. 1. These were significantly smaller than those of the experimental groups. During the first 15 days of the experiment, total cultivable microbes in the treatment groups increased and were faster than in T1 and T2 when compared to T3. On day 15, the number of total cultivable microbes in the treatment groups reached peaks of $2.036 \times 10^{10} \mathrm{cfu} / \mathrm{L}, 2.308 \times 10^{10} \mathrm{cfu} / \mathrm{L}$ and $9.88 \times 10^{9} \mathrm{cfu} / \mathrm{L}$, respectively. The content of total cultivable microbes continuously decreased from day 15 to day 30, and there was little change in those of T1 and T2 after day 30. At the end of the experiment, the number of total cultivable microbes in the treatment groups was higher than in the control. The difference between T1 and T2 was not detectable.

The total TSS and BFV in all treatments over time are shown in Fig.2 and Fig.3. Both TSS and BFV levels increased gradually throughout the experimental period, and their averages in $T 1$ and $T 2$ were around $510 \mathrm{mg} / \mathrm{L}$ and $55 \mathrm{ml} / \mathrm{L}$ on day 40 , respectively. However, both TSS and BFV levels were always very low in T3, and in the control they did not exceed $65.50 \mathrm{mg} / \mathrm{L}$ and $6.10 \mathrm{ml} / \mathrm{L}$, respectively. 


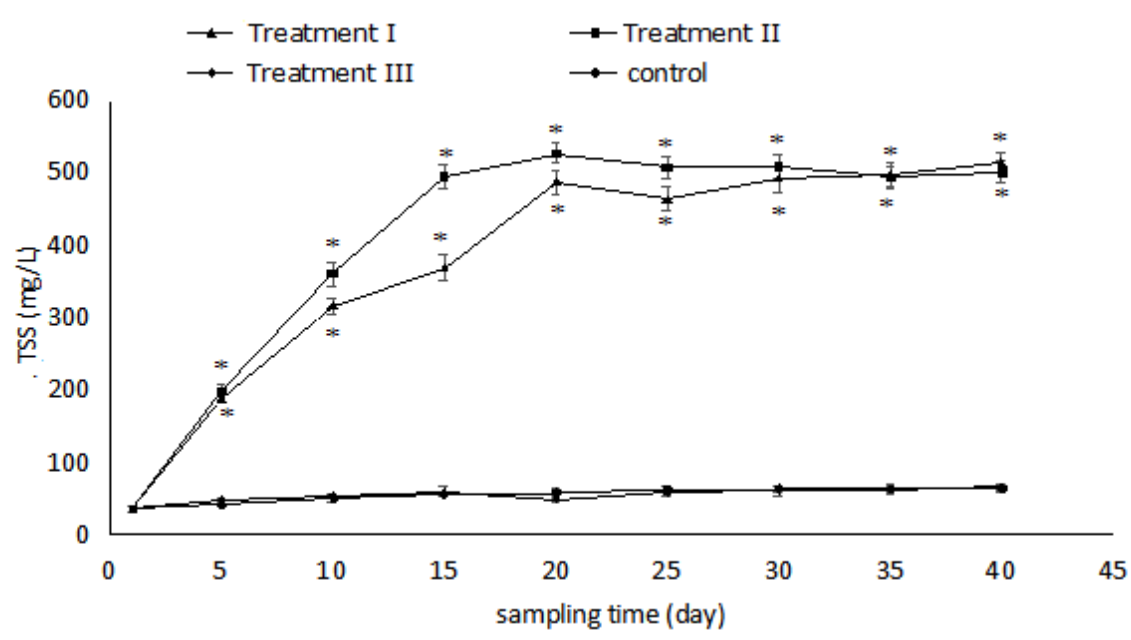

Fig 2. The change of the TSS in all aquaria during the experimental period. Values are means ( \pm S.D.) of three replicate aquariums per sampling time in each treatment. At the same time different superscript symbols $(*) \quad(p<0.05)$ denote significant differences within the treatments.

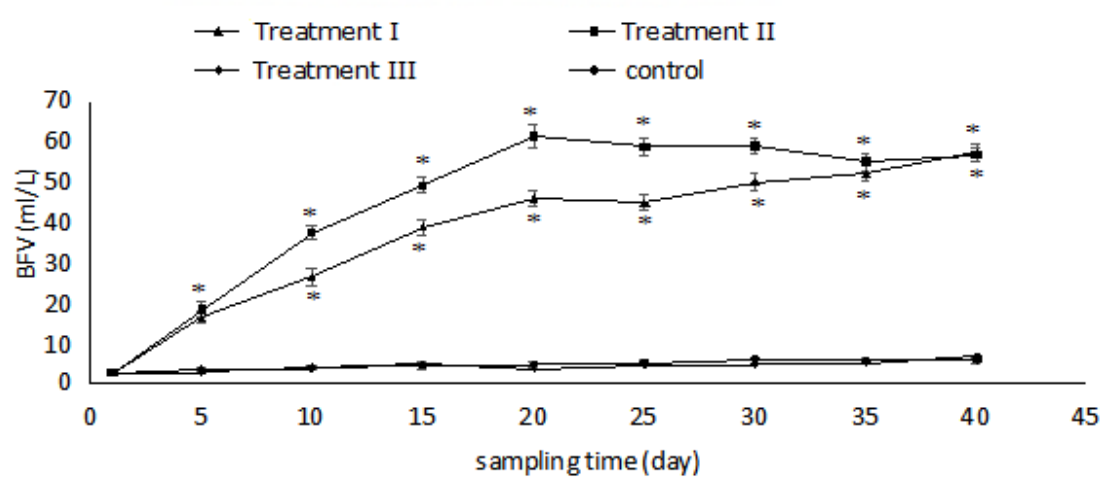

Fig 3. The change of the BFV in all aquaria during the experimental period.

The color of the biofloc sampled from the treatment aquaria was brown and of irregular structure and size (Fig. 4). When observed microscopically, the structure of the biological flocculation group changed from simple to complex, and the flocculation was composed of heterotrophic microorganisms, phytoplankton, zooplankton, and other species. 


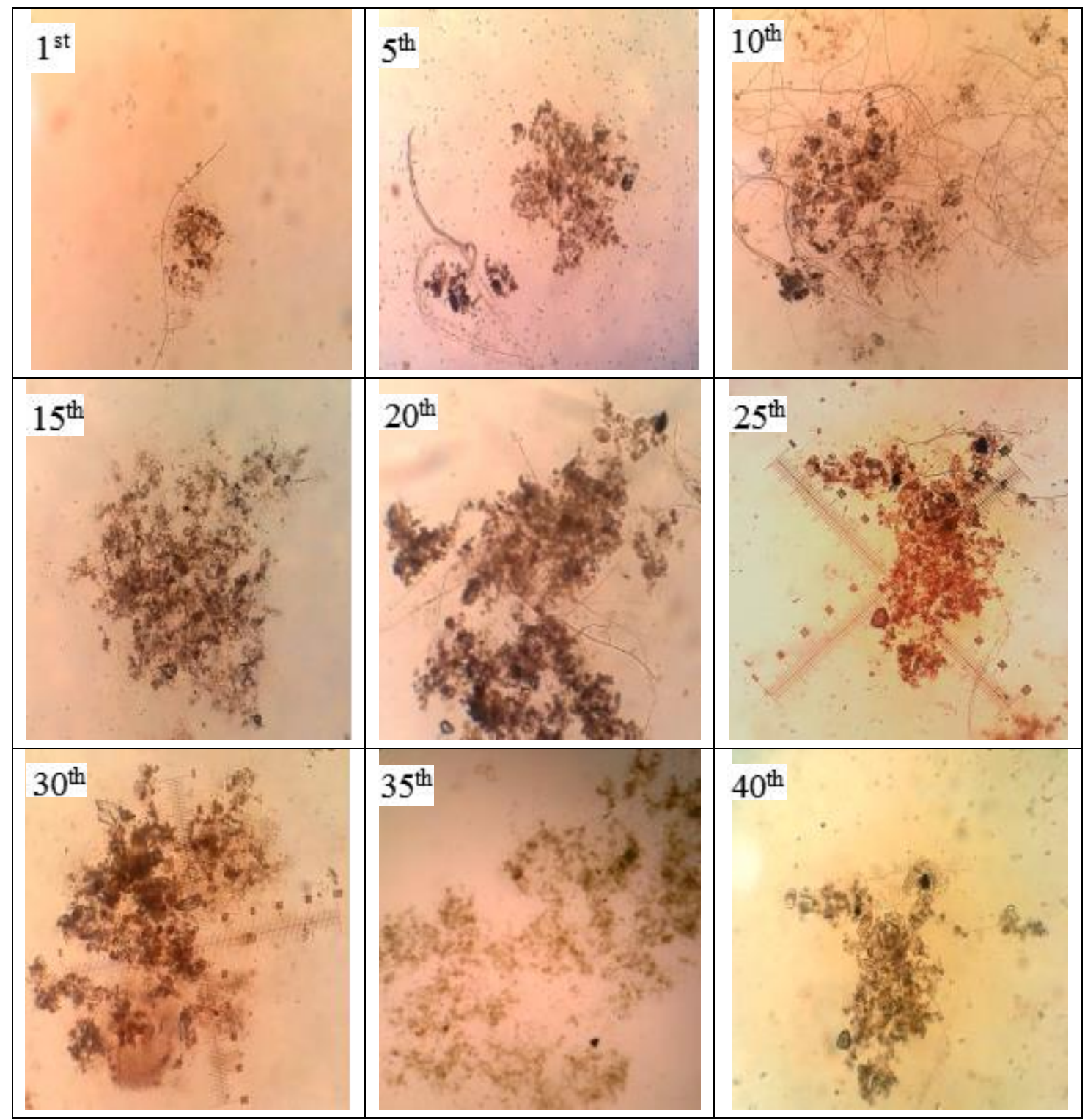

Fig 4. The microstructure of biofloc in different periods during the experimental period

Changes in the abundance of plankton. Prior to the addition of the pond water to the experimental aquaria, a microscopic evaluation of the pond water was performed which revealed the presence of several species of phytoplankton and zooplankton. The major categories of phytoplankton included Cyanobacteria, Chlorophyta, Euglenophyta and Cryptophyta. The major categories of the observed zooplankton were Protozoan, Rotifer, Cladocera and Copepods. The total density of phytoplankton in all aquaria is shown in Fig. 5 and the abundance of Cyanobacteria and Chlorophyta in Fig. 6 and Fig. 7, respectively.

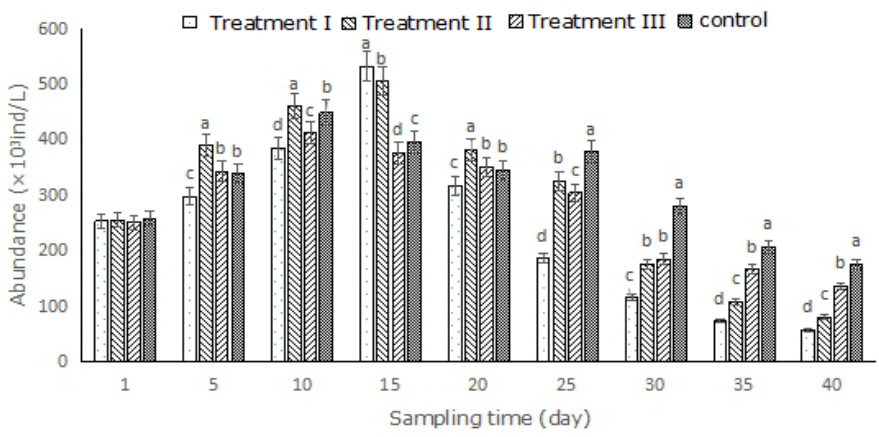

Fig 5. The total abundance of phytoplankton in all aquaria during the experimental period. 


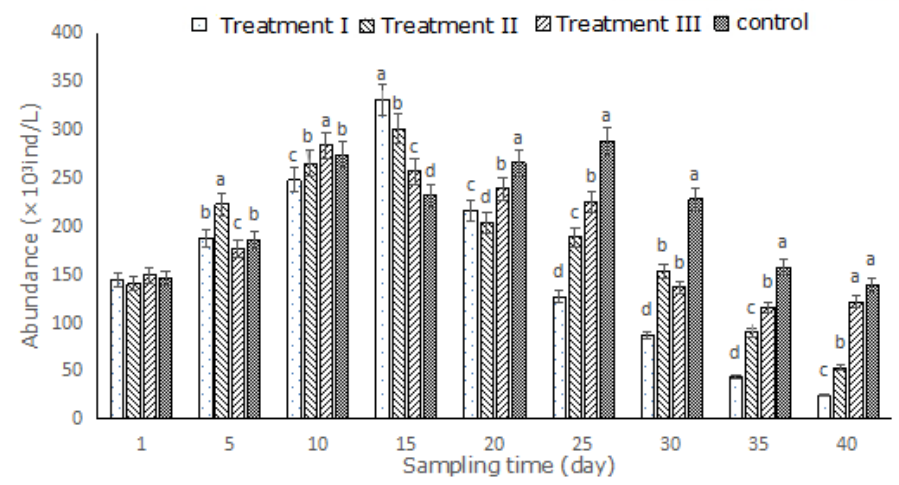

Fig 6. The total abundance of cyanobacteria in all aquaria during the experimental period. Values are means ( \pm S.D.) of three replicate aquaria per sampling time in each treatment

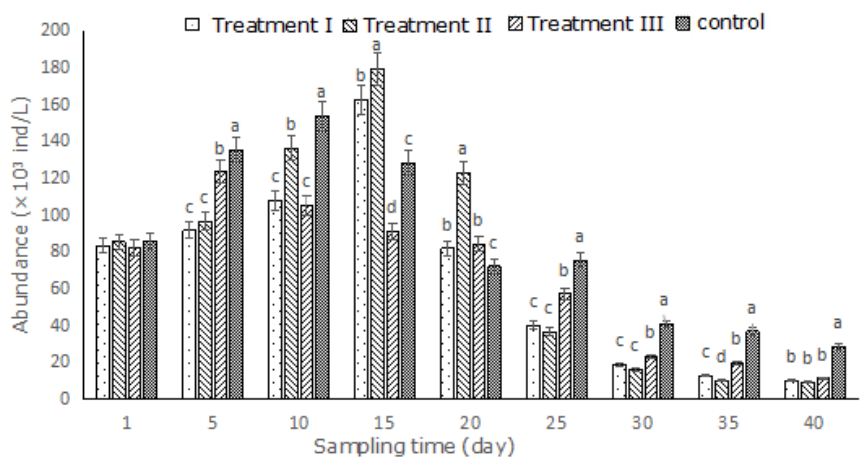

Fig.7. The total abundance of chlorophyta in all aquaria during the experimental period. Values are means ( \pm S.D.) of three replicate aquaria per sampling time in each treatment.

On day 5 , the abundance of phytoplankton in the $\mathrm{T} 2$ and control group reached the peak $5.560 \times 10^{5}$ ind/L and $4.485 \times 10^{5}$ ind/L, respectively. After day 15 , total abundance of phytoplankton in all aquaria (except for the control group) began to decrease. At the end of the experiment, phytoplankton in the treatment groups and in the control, reached $5.743 \times 10^{4}$ ind $/ L, 8.121 \times 10^{4}$ ind $/ L, 1.363 \times 10^{5}$ ind $/ L$ and $1.766 \times 10^{5}$ ind $/ L$, respectively. The number of total plankton in T1 and T2 was significantly lower $(P<0.05)$ than in T3 and the control group. The number of Cyanobacteria in the experiment is shown in Fig. 6 . In the first 15 days of the experiment, the number of cyanobacteria in each group increased significantly, and the rate of increase in T1 and T2 was significantly higher $(\mathrm{P}<0.05)$ than in the other groups. After 15 days, the number of cyanobacteria in $\mathrm{T} 1$ and T2 rapidly decreased and was reduced to $2.434 \times 10^{4} \mathrm{ind} / \mathrm{L}, 5.312 \times 10^{4} \mathrm{ind} / \mathrm{L}$ at the end of the experiment. The number of cyanobacteria in T3 and in the control group at the end of the experiment was $1.215 \times 10^{5}$ ind/L and $1.388 \times 10^{5}$ ind/L, respectively, and significantly higher $(P<0.05)$ than in the T1 and T2. The number of green algae in treatment groups and control group first increased and then decreased (Fig 8). The number of green algae in T1 and T2 reached peaks of $1.623 \times 10^{5}$ ind/L and $7.911 \times 10^{4}$ ind/L on day 15 , respectively, while the T3 and control group reached the maximum on day 5 and day 10 , with a maximum value of $1.235 \times 10^{5}$ ind/L and $1.537 \times 10^{5}$ ind/L. After day 15 , the number of green algae in all aquaria decreased in the treatment groups and were less than $1.2 \times 10^{4}$ ind $/ L$, compared to the control which reached $2.817 \times 10^{4}$ ind $/ L$, and was significantly higher $(\mathrm{P}<0.05)$ than the treatment groups. 


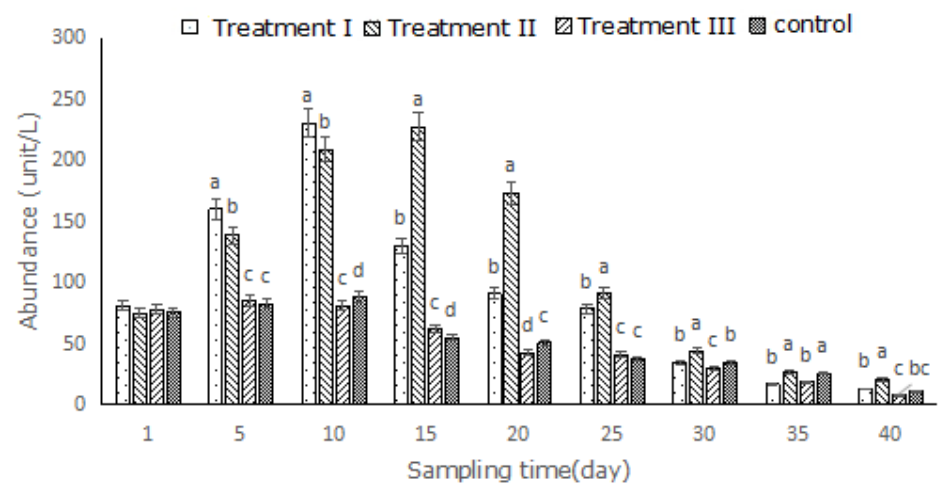

Fig 8. The abundance of protozoan in all aquaria during the experimental period. Values are means ( \pm S.D.) of three replicate aquaria per sampling time in each treatment.

The abundance of zooplankton appears in Fig 8-11. The number of protozoa in each group first increased and then decreased. In T1, T3 and the control group they reached a maximum on day 10 and in T2 on day 15 (Fig 8). The number of protozoa in T1 and T2 was significantly higher $(\mathrm{P}<0.05)$ than that in the T3 and control group from day 5 to day 25. At the end of the experiment, the number of protozoa in T2 was significantly higher $(P<0.05)$ than that of the other groups.

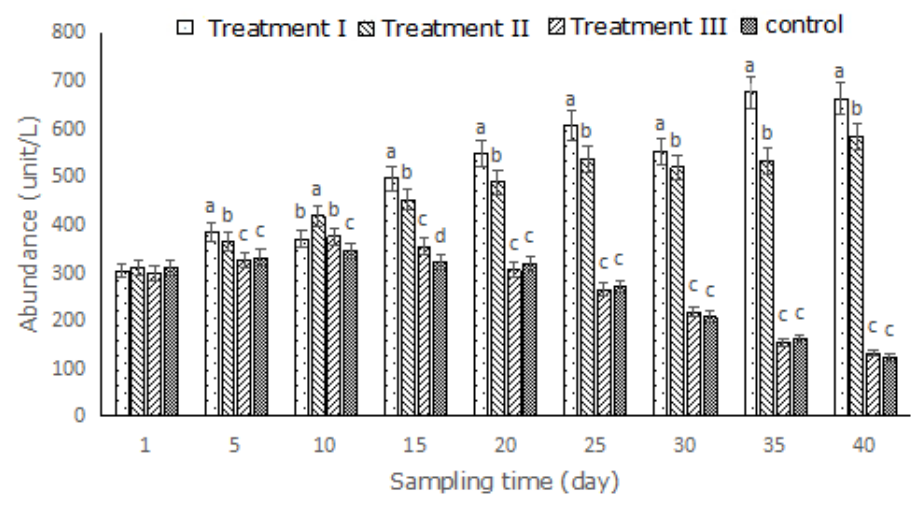

Fig 9. The abundance of Rotatoria in all aquaria during the experimental period. Values are means ( \pm S.D.) of three replicate aquaria per sampling time in each treatment.

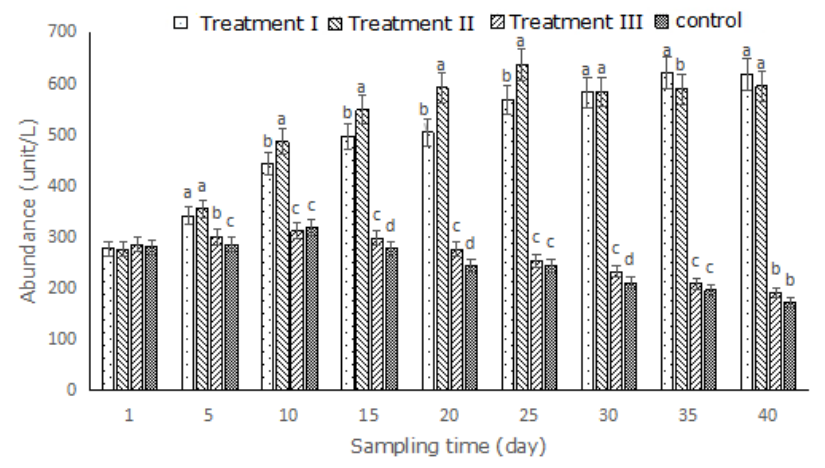

Fig10. The abundance of copepods in all aquaria during the experimental period. Values are means $( \pm S . D$.$) of three replicate aquaria per sampling time in each treatment.$ 


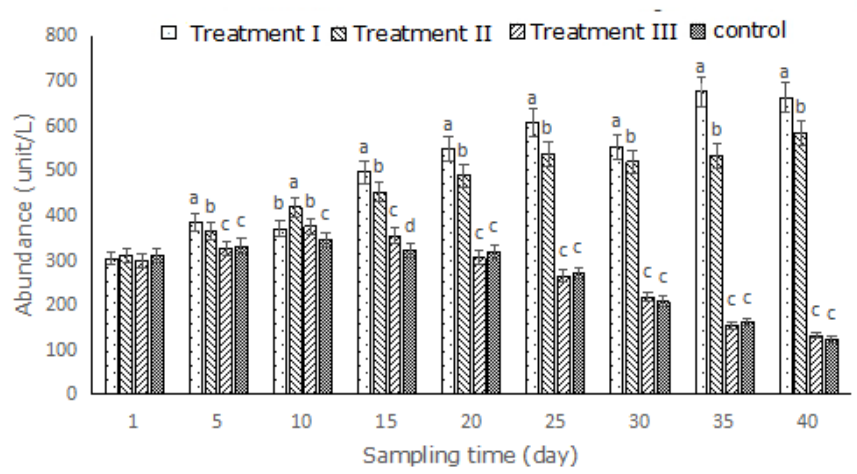

Fig 11.The abundance of cladocera in all aquaria during the experimental period. Values are means ( \pm S.D.) of three replicate aquaria per sampling time in each treatment.

The changes of the number of rotifers in all aquaria during the experimental period appear in Fig 9. T1 and T2 exhibited a rising trend. On the other hand, the number of rotifers in T3 and the control group decreased. At the end of the experiment, the number of rotifers in T1 was the greatest and in the control group was the least. There was no significant difference $(P>0.05)$ between the T3 and control group. There was a significant difference in the number of rotifers in T1 and T2 compared with other groups $(\mathrm{P}<0.05)$. The number of copepods in $\mathrm{T} 1$ and $\mathrm{T} 2$ showed an upward trend and in T3 and the control group it decreased (Fig 10). There was no significant difference $(P>0.05)$ in the number of copepods between T3 and the control. After day 10, the number of copepods in the T1 and T2 was significantly higher $(P<0.05)$ than in T3 and the control. The number of copepods in T1, T2, T3 and control group was 618 unit/L, 594 unit/L, 191 unit/L and 172 unit/L respectively. The number of cladocera is shown in Fig 11. Their numbers in T1 and T2 first increased and then decreased, while in T3 and the control group they decreased slowly. In T1 they reached a maximum (168 unit/L) on day 25 , and in T2 (194 unit/L) on day 20 . By day 40 , the numbers of cladocera in T1, T2, T3 and control group were 83 unit/L, 68 unit/L, 6 unit/L and 8 unit/L, respectively.

\section{Discussion}

In the current study, the level of $\mathrm{DO}$ and $\mathrm{pH}$ values in $\mathrm{T} 1$ and the $\mathrm{T} 2$ groups were lower than that in the T3 and control group. The lower levels of DO and $\mathrm{pH}$ values were possibly a result of the glucose addition that was consumed by a large number of microorganisms (heterotrophic community), resulting in rapid growth and high respiration rates. Similar results were observed by Tacon et al. (2002) and Wasielesky et al. (2006). Similarly, a decrease in pH during the chemolithotrophic nitrification process as a result of $\mathrm{CaCO}_{3}$ consumption and the release of $\mathrm{CO}_{2}$ and $\mathrm{H}^{+}$into the culture medium was reported (Chen et al. 2006; Ebeling et al. 2006; and Rijn et al. 2006). There was no significant difference in the content of DO in T3 and the control group suggesting that the addition of Bacillus subtilis had no significant effect on the DO levels.

Ammonia and nitrite are highly toxic to aquatic animals, though their toxicity is species specific and depends on water characteristics and the duration of exposure (Tomasso, 1994; Hargreaves 1998; Barajas et al., 2006; Mishra et al., 2008). In general, when the concentration of ammonia nitrogen in aquaculture water column is greater than $1 \mathrm{mg} / \mathrm{L}$, and $\mathrm{NO}^{-}-\mathrm{N}$ concentration reaches about $10 \mathrm{mg} / \mathrm{L}$, the aquatic animals are stressed. When the carbon and nitrogen ratio is 10 in the water, the microbial biomass attached to the biofloc is assimilated and absorbed at a rate of $0.2 \mathrm{~g}$ per square meter (Azim et al. 2008). In our study, the carbon and nitrogen ratio in the T1 and the T2 was 20, which was twice that reported by Azim (2008). The contents of ammonia nitrogen and $\mathrm{NO}^{-}-\mathrm{N}$ in $\mathrm{T} 1$ and $\mathrm{T} 2$ were lower than those in $\mathrm{T} 3$ and control group after day 15 . This result suggests that the input of glucose in $\mathrm{T} 1$ and $\mathrm{T} 2$ enhanced the accumulation of particulate organic matter in the aquaria in these treatments, and C:N ratio was 20:1 and efficiently converted the $\mathrm{NO}^{-}-\mathrm{N}$ into microbial protein (Avnimelech, 1999). Nevertheless, the levels of ammonia and nitrite observed in this study were below lethal levels. Biofloc systems may enhance the production of dense microbial communities that 
affect the amount of ammonia released by the cultivated organisms (Avnimelech (1999). Ammonia can be absorbed by micro-algae, by heterotrophic bacteria, or can be transformed by nitrifying bacteria (Ebeling et al., 2006). The growth of these organisms appears in the form of biofloc (De Schryver et al., 2008). This result indicates that the addition of glucose to the cultivation of biofloc effectively reduces the content of $\mathrm{NH}_{4}{ }^{+}-\mathrm{N}$ and $\mathrm{NO}^{-}-\mathrm{N}$ in the culture water.

Our results confirmed that adding glucose to the water column significantly promotes the growth of heterotrophic microorganisms. In biofloc systems, carbohydrate addition promotes the development of diverse and balanced microbial communities (Haslun et al., 2012). These active and dense microorganisms together with suspended organic particles form bioflocs, which are a natural food source consumed by animals in culture (Burford et al., 2004; Wasielesky et al., 2006). In the present experiment, there were no aquatic animals. Therefore, our results showed the net potential of the system. As shown in Fig 2 , the amount of BFV and TSS in T1 and T2 were the same. The total amount of the BFV and the TSS in the T1 and the T2 reached the maximum on day 20 . The biofloc particle size ranged from 0.3 to $5 \mathrm{~mm}$, similar to the result of Xu et al. (2013), and reached a peak on day 20, that can benefit fish and crustaceans in cultures. The same results were also obtained by Wang et al. (2016).

By adding glucose to the water even in the zero-water exchange applied in this system, water quality was significantly improved, the ammonia nitrogen, $\mathrm{NO}^{-}-\mathrm{N}$ remained at a relatively low level demonstrating that this may be more widely used in aquaculture. In this study, the total abundance of phytoplankton first increased and then decreased in the treatment groups, in particular, the change of the number of cyanobacteria and green algae in the experiment suggesting that the biological flocculation had an inhibitory effect on cyanobacteria and green algae in the water column.

Zooplankton is an important part of aquaculture water. In T1 and the T2, the number of protozoan and copepods first increased and then decreased. In T3 and the control, they were significantly lower than in $\mathrm{T} 1$ and $\mathrm{T} 2$. This suggests that the addition of carbohydrates to the water promoted the growth of heterotrophic microorganisms (Schneider et al. 2006), and increased the microbial community on which heterotrophic microorganisms feed (Avnimelech, 1999; Crab et a1., 2009).

\section{Conclusion}

The results of this study indicated that biofloc is formed by adding glucose into the culture water. Bacillus subtilis shortens the time of mature biofloc formation by about 5 days. The $\mathrm{NH}_{4}{ }^{+}-\mathrm{N}$ and $\mathrm{NO}^{-}-\mathrm{N}$ levels in the water column decreased and the number of cyanobacteria and green algae were inhibited, while the number of zooplankton such as rotifers increased. The results of this experiment broadened the basis and value of similar systems.

\section{Acknowledgments}

This work has been financially supported by the Technology Research and Development Department of BIOMAX Ecological Engineering Limited by Share Ltd and Natural Science Foundation of Hubei Province (No. 2016CFB176). We thank the staff at the Laboratory of Nutrition Physiology of Aquatic Animal for their assistance in conducting the experiment and Professor Ya-Xiong Tao (Auburn University, Auburn, AL, USA) for surpervising the manuscript.

\section{References}

Avnimelech, Y., 1999. Carbon/nitrogen ratio as a control element in aquaculture systems. Aquaculture, 176:227-235.

Avnimelech, Y., 2007. Feeding with microbial flocs by tilapia in minimal discharge bioflocs technology ponds. Aquaculture, 264:140-147.

Avnimelech Y., Kochva M. \& Diab S., 1999. Development of controlled intensive aquaculture systems with limited water exchange and adjusted carbon to nitrogen ratio. Isr. J.Aquacult.-Bamidgeh, 46:119-131.

Azim ME, Little DC., 2008. The biofloc technology (BFT) in indoor aquariums: water quality, biofloc composition, and growth and welfare of Nile tilapia (Oreochromis niloticus). Aquaculture, 283:29-35. 
Barajas FM, Villegas RS, Clark GP, Mosqueda JG, Moreno BL., 2006. Daily variation in short-term static toxicity of unionized ammonia in Litopenaeus vannamei (Boone) postlarvae. Aquacult. Res., 37:1406-1412.

Burford, M.A., Thompson, P.J., McIntosh, R.P., Bauman, R.H., Pearson, D.C., 2003. The contribution of flocculated material to shrimp (Litopenaeus vannamei) nutrition in a high-intensity, zero-exchange system. Aquaculture, 232:525-537.

Browdy C.L., Bratvold D., Stokes A.D. \& Mcintosh R.P., 2001. Perspectives on the application of closed shrimp culture systems. In:The New Wave, Proceedings of the Special Session on Sustainable Shrimp Culture(ed. by E.D. Jory \& C.L.Browdy), The World Aquaculture Society, Baton Rouge, LA, USA.20-34 pp.

Crab, R., Kochba, M., Verstraete, W., Avnimelech, Y., 2009. Bioflocs technology application in over-wintering of tilapia. Aquacult. Eng., 40:105-112.

De Schryver P., Crab R., Defoirdt T., Boon N. \& Verstraete W., 2008. The basics of bioflocs technology: the added value for aquaculture. Aquaculture, 277:125-137.

Ebeling JM, Timmons MB, Bisogni JJ., 2006. Engineering analysis of the stoichiometry of photoautotrophic, autotrophic and heterotrophic removal of ammonia-nitrogen in aquaculture systems. Aquaculture, 257:346-358.

Haslun, J., Correia, E., Strychar, K., Morris, T., Samocha, T., 2012. Characterization of bioflocs in a no water exchange super-intensive system for the production of food size pacific white shrimp Litopenaeus vannamei. Aquacult. Int., 2:29-38.

Hargreaves, J.A., 2006. Photosynthetic suspended-growth systems in aquaculture. Aquacult. Eng., 34:344-363.

Mishra JK, Samocha TM, Patnaik S, Speed M, Gandy RL, Ali A., 2008. Performance of an intensive nursery system for the Pacific white shrimp, Litopenaeus vannamei, under limited discharge condition. Aquacult. Eng., 38:2-15.

Neori, A., Chopin, T., Troell, M., Buschmann, A.H., Kraemer, G.P., Halling, C.,

Shpigel, M.,Yarish, C., 2004. Integrated aquaculture: rationale, evolution and state of the art emphasizing seaweed biofiltration in modern mariculture. Aquaculture, 231:361391.

Rijn JV, Tal Y, Schreier HJ., 2006. Denitrification in recirculating systems: theory and applications. Aquacult. Eng., 34:364-376.

Stokstad, E., 2010. Down on the shrimp farm. Science, 328:1504-1505.

Samocha T.M., Patnaik S., Speed M., Ali A.M., Burger J.M.,Almeida R.V., Ayub Z., Harisanto M., Horowitz A. \&Brock D.L., 2007. Use of molasses as carbon source in limited discharge nursery and grow-out systems for Litopenaeus vannamei. Aquacult. Eng., 36:184-191.

Schneider, O., Sereti, V., Machiels, M.A.M., Eding, E.H., Verreth, J. A.J., 2006. The potential of producing heterotrophic bacteria biomass on aquaculture waste. Water Res., 40:2684-2694.

Tacon AGJ, Cody JJ, Conquest LD, Divakaran S, Forster IP, Decamp OE., 2002. Effect of culture system on the nutrition and growth performance of Pacific white shrimp Litopenaeus vannamei (Boone) fed different diets. Aquacult. Nutr., 8:121-137.

Tomasso JR., 1994. Toxicity of nitrogenous wastes to aquaculture animals. Rev Fish Sci, 2:291-314.

Thompson F.L., Abreu P.C. \& Wasielesky W., 2002. Importance of biofilm for water quality and nourishment in intensive shrimp culture. Aquaculture, 203:263-278.

Wasielesky W, Atwood H, Stokes A, Browdy CL., 2006. Effect of natural production in a zero exchange suspended microbial floc-based super-intensive culture system for white shrimp Litopenaeus vannamei. Aquaculture, 258:396-403.

Xu, W.J., Pan, L.Q., 2012. Effects of bioflocs on growth performance, digestive enzyme activity and body composition of juvenile Litopenaeus vannameiin zero-water exchange aquariums manipulating C/N ratio in feed. Aquaculture, 357:147-152.

Wang Chaohui., 2016.Study on Glucose Addition on Water Environmental Control for the Zero-water Exchange Shrimp Culture System. Shanghai Ocean University, Shanghai. 